\title{
Evaluation of the wind power potential in the European nearshore of the Mediterranean Sea
}

\author{
Eugen Rusu ${ }^{1, *}$ and Liliana Rusu ${ }^{1}$ \\ ${ }^{1}$ Department of Mechanical Engineering, 'Dunarea de Jos' University of Galati, 47 Domneasca St., 800008 Galati, Romania
}

\begin{abstract}
In the last years, the offshore wind sector has been constantly growing in Europe, coming also with a very competitive production price. The objective of this paper is to evaluate the wind power potential in the European coastal environment of the Mediterranean Sea, an area with a high population density. Furthermore, a high energy demand exists here and the potential of the renewable energy resources needs to be assessed for further exploitation. The analysis was performed considering some reference locations. The climate change impact on the wind energy resource is also investigated. Various comparisons between historical data and future climate projections simulated by a Regional Climate Model under RCP4.5 scenario are made. The results obtained show that in various locations, especially in Golf of Lion and the Aegean Sea, there are appropriate conditions for offshore wind exploitations.
\end{abstract}

\section{Introduction}

It is well known that the greenhouse gas emissions need to be reduced due to their effect on global warming and to the subsequent damages produced by it. One measure made by Europe was to promote, and also to support, the production of electricity from renewable sources. In these conditions, the EU has agreed a $32 \%$ renewable energy target to 2030, with an upward review clause in 2023 , that equals around $55 \%$ of electricity coming from renewables in 2030 [1].

The marine environment is a plentiful source of renewable energy that can be harvested from waves, offshore winds, tides or currents. Taking in consideration various factors as, the development of the technology or the capacity of the installed devices, the offshore wind energy seems to be the most mature type of renewable energy extraction in the marine environment [2]. International Renewable Energy Agency (IRENA) also pointed out that the offshore wind energy is having a rapid technology cost reduction among others due to the advances in offshore wind turbine technology, wind farm development or increasing developer experience [3]. Global Wind Energy Council (GWEC) noticed also that 2017 was a spectacular year for offshore wind sector with new installed capacities around 4.333 MW (installed in nine markets globally), representing a $95 \%$ increase compared with 2016. At the end of 2017, approximatively $84 \%$ of the overall offshore installations (offshore wind capacity 18,814 MW) were placed in the waters off the coast of European countries, but the offshore industry expansion across other markets has begun and has a rapid development [4].

The European coastal environment of the Mediterranean Sea is an area with a high population density. Subsequently, a high energy demand exists here and the potential of the renewable energy resources need to be assessing for further exploitation. Moreover, until now no offshore wind farms have been deployed in the Mediterranean waters although some previous studies indicated it to have suitable wind potential [5-7]. The new technology developments of the floating wind farms open the perspective to be exploited the potential of deep-water offshore wind power. This can be relevant for the Mediterranean countries having large water depths at a short distance from the shore [8].

For this reason, extended evaluations of the wind power potential in this area need to be made in order to find the locations having the capacity to become interesting for future expansions of the offshore wind emplacements [9]. These evaluations can be made based on the wind speed information retrieved from measurements or numerical modelling of the wind fields over the target area $[10,11]$. The wind fields, and also the wind energy, are affected by climate changes [12-14]. For the new investments, it is important to know what the projections of the wind energy in the target area indicate for the coming years. The resolution of the wind fields is also very important for the accuracy of data $[15,16]$

In this study, the wind energy power in some reference locations of the Mediterranean Sea is evaluated using the wind fields provided by a Regional Climate Model (RCM) for two climate periods of 30-year timeslice each. These time-slices cover the historical (19762005) and the mid- $21^{\text {st }}$ century (2021-2050) wind conditions. The climate change impact on the wind energy resource is also investigated by means of various comparisons between historical data and future climate projections under a Representative Concentration

Corresponding author: erusu@ugal.ro

(c) The Authors, published by EDP Sciences. This is an open access article distributed under the terms of the Creative Commons Attribution 
Pathways (RCP) that considers an intermediate concentration scenario, namely RCP4.5 [17]. In this way, a perspective of the future wind power potential in the chosen locations will be obtained.

\section{Materials and methods}

\subsection{Target area}

The target areas of the present study are the European coastal environments of the Mediterranean Sea. Some reference locations (12 points) covering the nearshore of European countries were chosen in various subdivisions of the Mediterranean basin, as presented in Figure 1. Details about the geographical positions of these points and their characteristics are given in Table 1.

Table 1. The geographical locations and the characteristics of the reference points.

\begin{tabular}{|c|c|c|c|c|}
\hline Points & $\begin{array}{c}\text { Latitude } \\
\mathbf{(}^{\circ}\end{array}$ & $\begin{array}{c}\text { Longitude } \\
\left({ }^{\circ}\right)\end{array}$ & $\begin{array}{c}\text { Distance to } \\
\text { shore (km) }\end{array}$ & $\begin{array}{c}\text { Sea depth } \\
(\mathbf{m})\end{array}$ \\
\hline M1 & N36.75 & E2.45 & 6.8 & 126 \\
\hline M2 & N41.10 & E1.46 & 8.4 & 137 \\
\hline M3 & N43.23 & E4.77 & 11.2 & 82 \\
\hline M4 & N41.47 & E9.62 & 22 & 146 \\
\hline M5 & N41.12 & E13.38 & 14.4 & 120 \\
\hline M6 & N37.43 & E12.86 & 16 & 112 \\
\hline M7 & N36.00 & E14.27 & 6.4 & 107 \\
\hline M8 & N41.51 & E16.67 & 28 & 88 \\
\hline M9 & N35.55 & E23.68 & 6.5 & 92 \\
\hline M10 & N37.85 & E24.35 & 14 & 82 \\
\hline M11 & N38.10 & E26.77 & 6.2 & 76 \\
\hline M12 & N34.67 & E32.52 & 4 & 55 \\
\hline
\end{tabular}

The points are denoted from west to east, thus M1 is on the southern coast of Spain (Alboran Sea), while M2 and M3 are in the Balearic Sea on the Spanish coast (near Barcelona) and in Gulf of Lion on the French coast, respectively. The point M4 and M5 are in the Tyrrhenian Sea, first between Sardinia and Corsica islands, while the second near the southern Italian coast (close to Napoli). In the south-western side of Sicily (Sea of Sicily) is the point M6, while near to Malta can find M7. Near to the southern-eastern coast of Italy at the Adriatic Sea is M8, while M9 is in the Sea of Crete (Kissamos Bay). The points M10 and M11 are in the southern part of the Aegean Sea, near to the Greece and Turkey coasts, respectively. The twelfth point M12 is on the south-western coast of the Cyprus Island, in the Levantine Sea.

Besides the fact that these locations cover the coastal areas of various European countries, they were also chosen on basis of the results of previous studies that indicated the surrounding areas as being characterized by elevated wind speeds $[5,10]$. The regime of the wind conditions over the Mediterranean basin was analysed in some previous studies $[18,19]$ that pointed out the western side of the basin as being characterized by more energetic conditions.

\subsection{Datasets}

The EURO-CORDEX database is the European branch of the Coordinated Regional Downscaling Experiment (CORDEX) and provides high-resolution wind fields simulated by various RCMs [20,21]. These fields contain information about the wind speed components at $10 \mathrm{~m}$ height ( $U_{10}$ denotes the wind speed) and cover the European zone. They have a spatial and temporal resolution of $0.11^{\circ}$ and 6 hours, respectively.

The wind fields simulated by Rossby Centre regional climate model - RCA4 model [22] at SMHI (Swedish Meteorological and Hydrologic Institute), forced with initial and lateral boundary conditions provided by ECEARTH Global Climate Model (GCM), are used in this study. First datasets considered are the historical winds that cover a 30-year period, from 1976 to 2005. The second datasets cover the 30-year interval from 2021 to 2050 and they are projections of the future wind fields simulated by the RCA4 model under RCP4.5 scenario. This scenario describes an intermediate concentration scenario with radiative forcing stabilized at around 4.5 $\mathrm{W} / \mathrm{m}^{2}$ at the end of the $21^{\text {st }}$ century.

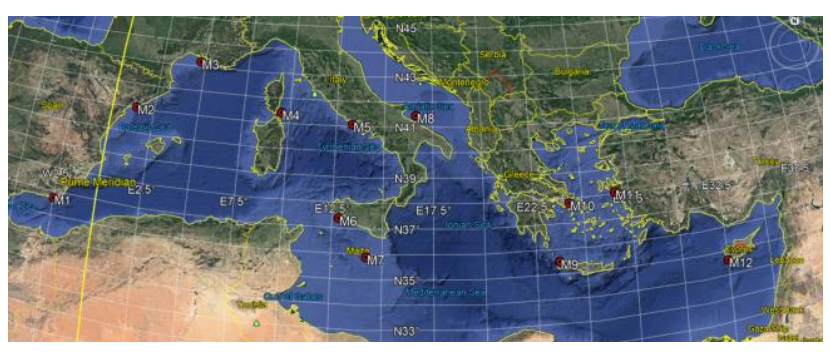

Fig. 1. Map of the Mediterranean Sea and the reference sites marked with red circles (from Google Earth, 2019).

\section{Analysis of the wind power}

In order to perform an evaluation of the wind power potential in the Mediterranean Sea, the wind power density $P\left(\mathrm{~W} / \mathrm{m}^{2}\right)$ per unit of the swept area needs to be computed based on the information regarding the wind speed. The relationship used is [23]:

$$
P=\frac{1}{2} \rho_{\text {air }} U_{z}^{3}
$$

with $\rho_{\text {air }}$ the air density has the value of $1.225 \mathrm{~kg} / \mathrm{m} 3$ and $U_{\mathrm{z}}$ being the wind speed at a height $z$.

Databases usually provide the wind velocity at a height of $10 \mathrm{~m}$ over the sea level, but nowadays the typical height for offshore wind exploitation is around 80 $\mathrm{m}$, or even more [24]. In order to compute the wind speed at the high level where the wind turbines are estimated to operate, a logarithmic law is considered [25]. This approach established that the wind speed $U_{\mathrm{z}}$ (in the present case $z$ is considered to be $80 \mathrm{~m}$ ) can be expressed as: 


$$
U_{z}=U_{\text {zref }} \frac{\ln \left(z / z_{0}\right)}{\ln \left(z_{\text {ref }} / z_{0}\right)}
$$

where $U_{\text {zref }}$ is, in fact, the known wind speed $U_{10}$ at the height $z_{\text {ref }}$ (in this case $10 \mathrm{~m}$ ), while the value of the sea surface roughness length $z_{0}$ is taken $0.0002 \mathrm{~m}$ over the sea.

At the twelve reference points, $U_{10}$ were computed from EURO-CORDEX wind fields using a trianglebased linear interpolation method. After this, $U_{80}$ and $P$ were computed in each point, and for each 30-year period considered, considering the historical wind fields and also the projections under RCP4.5 scenario. The values obtained for wind power were analysed using some statistical parameters in order to obtain an overview of wind energy potential in the Mediterranean Sea by means of the results in the reference points.

The statistical parameters considered are: Mean mean value, Max - maximum value, Std - standard deviation, Skew - skewness index, $50^{\text {th }}$ and $95^{\text {th }}-50$ and 95 percentile. The standard definitions were used for the computation of all statistical parameters. To be mentioned that the 95 percentile represents, in this case, the wind power value below which $95 \%$ of the values may be found, while 50 percentile represent also the median value. The results obtained for historical data (1976-2005) are presented in Table 2, while for RCP4.5 data (2021-2050) are shown in Table 3

The results presented in Table 2 show that the highest mean wind power for the historical period are found in the points M1, M3, M4, M6, M8 and M10, with values higher than $400 \mathrm{~W} / \mathrm{m}^{2}$ (various studies considered the wind power potential as very good above this limit [10]). In the case of the projections under RCP4.5 scenario, only in five points, the means are higher the above limit mentioned (the exception is point M6, in this case presenting a mean wind power about $388 \mathrm{~W} / \mathrm{m}^{2}$ ). For both period analysed the highest mean value was found in M3, with 724 and $720 \mathrm{~W} / \mathrm{m}^{2}$, respectively.

Table 2. Wind power characteristics corresponding to the reference points computed for the 30-year period 1976-2005.

\begin{tabular}{|c|c|c|c|c|c|c|}
\hline Points & $\begin{array}{c}\text { Mean } \\
\left(\mathbf{W} / \mathbf{m}^{2}\right)\end{array}$ & $\begin{array}{c}\text { Max } \\
\left(\mathbf{W} / \mathbf{m}^{2}\right)\end{array}$ & $\begin{array}{c}\text { Std } \\
\left(\mathbf{W} / \mathbf{m}^{\mathbf{2}}\right)\end{array}$ & $\begin{array}{c}\mathbf{5 0}^{\text {th }} \\
\left(\mathbf{W} / \mathbf{m}^{\mathbf{2}}\right)\end{array}$ & $\begin{array}{c}\mathbf{9 5}^{\text {th }} \\
\left(\mathbf{W} / \mathbf{m}^{\mathbf{2}}\right)\end{array}$ & Skew \\
\hline M1 & 418 & 11743 & 642 & 162 & 1653 & 3.35 \\
\hline M2 & 143 & 23250 & 302 & 40 & 642 & 13.95 \\
\hline M3 & 724 & 13607 & 975 & 353 & 2662 & 2.75 \\
\hline M4 & 620 & 12012 & 829 & 306 & 2259 & 2.65 \\
\hline M5 & 298 & 9218 & 516 & 105 & 1278 & 4.05 \\
\hline M6 & 400 & 13349 & 633 & 176 & 1595 & 3.97 \\
\hline M7 & 285 & 10015 & 501 & 86 & 1236 & 4.02 \\
\hline M8 & 410 & 12677 & 627 & 180 & 1586 & 3.76 \\
\hline M9 & 225 & 11853 & 375 & 88 & 912 & 4.62 \\
\hline M10 & 437 & 8516 & 619 & 190 & 1709 & 2.79 \\
\hline M11 & 302 & 7886 & 423 & 150 & 1091 & 3.39 \\
\hline M12 & 241 & 9959 & 400 & 115 & 887 & 5.41 \\
\hline
\end{tabular}

Table 3. Wind power characteristics corresponding to the reference points computed for the 30-year period 2021-2050.

\begin{tabular}{|c|c|c|c|c|c|c|}
\hline Points & \begin{tabular}{|c|} 
Mean \\
$\left(\mathbf{W} / \mathbf{m}^{2}\right)$ \\
\end{tabular} & $\begin{array}{c}\text { Max } \\
\left(\mathbf{W} / \mathbf{m}^{2}\right)\end{array}$ & $\begin{array}{c}\text { Std } \\
\left(\mathbf{W} / \mathbf{m}^{2}\right)\end{array}$ & $\begin{array}{c}50^{\text {th }} \\
\left(\mathbf{W} / \mathbf{m}^{2}\right) \\
\end{array}$ & $\begin{array}{c}95^{\text {th }} \\
\left(\mathrm{W} / \mathbf{m}^{2}\right) \\
\end{array}$ & Skew \\
\hline M1 & 420 & 12398 & 685 & 154 & 1692 & 3.81 \\
\hline M2 & 141 & 6339 & 301 & 38 & 642 & 5.08 \\
\hline M3 & 720 & 14691 & 1007 & 332 & 2674 & 2.87 \\
\hline M4 & 604 & 11665 & 832 & 285 & 2238 & 2.79 \\
\hline M5 & 286 & 19053 & 517 & 100 & 1212 & 5.25 \\
\hline M6 & 388 & 8720 & 601 & 169 & 1554 & 3.41 \\
\hline M7 & 272 & 7934 & 469 & 79 & 1198 & 3.54 \\
\hline M8 & 419 & 11036 & 625 & 185 & 1599 & 3.61 \\
\hline M9 & 231 & 7791 & 373 & 91 & 921 & 4.07 \\
\hline M10 & 446 & 9556 & 624 & 197 & 1727 & 2.76 \\
\hline M11 & 316 & 6507 & 424 & 161 & 1105 & 3.12 \\
\hline M12 & 237 & 14062 & 391 & 111 & 889 & 6.52 \\
\hline
\end{tabular}

In order to observe inter-annual the variability of the wind power along each 30 -year period, the annual means were computed in all reference points. Figure 2 presents the results only for M3. The possible trends of the annual data can be highlighted by fitting a linear trend (dashed blue line) or applying a five-year running average filter (solid black line).
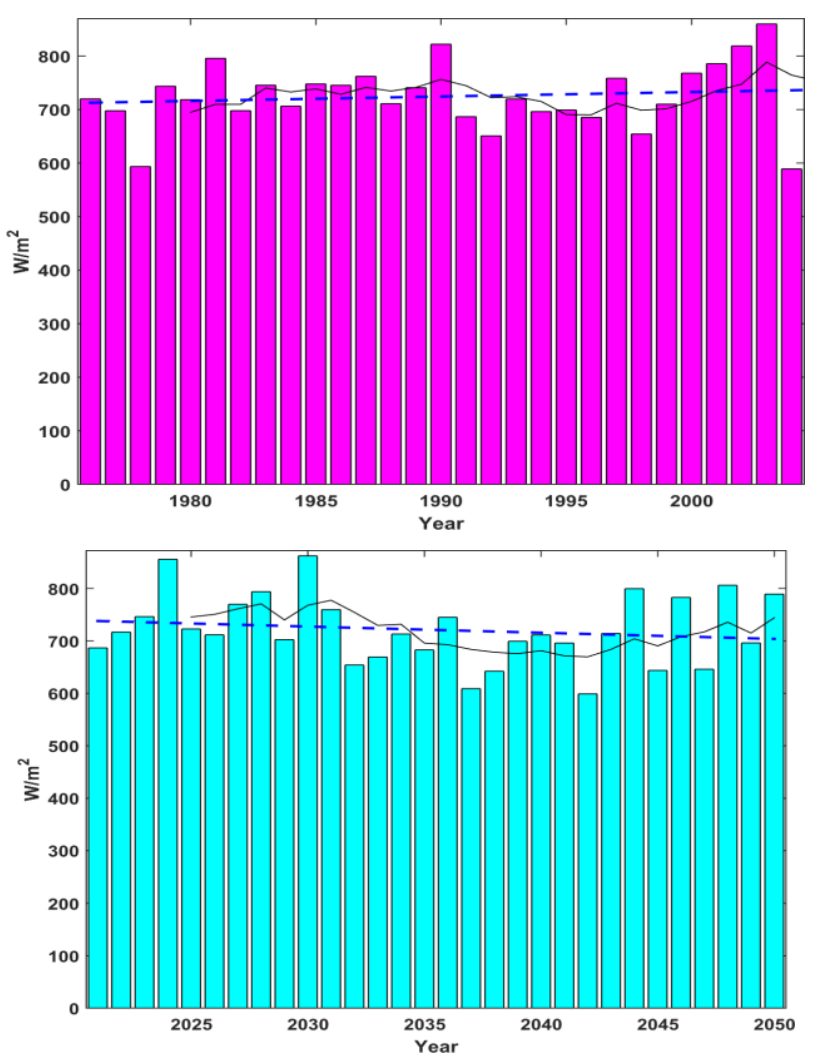

Fig. 2. Annual means of the wind power at the height of $80 \mathrm{~m}$ above the sea level for the point M3 computed for historical data (top panel) and for RCP4.5 (bottom panel). The linear trend is indicated by the blue dashed line.

The slope of the linear regression adjusted to the annual means for historical data indicates a slight 
increase of the annual means (about $8 \mathrm{~W} / \mathrm{m}^{2}$ per decade), while in the case of projections under RCP4.5 scenario seems to appear a decrease of the wind power (about 12 $\mathrm{W} / \mathrm{m}^{2}$ per decade).

Along the months of the year, the wind power can also present some variability. In order to observe come features of the wind power in the reference locations, the monthly means were computed and the results are shown in Figure 3. First of all, it can be observed that between the historical monthly averages (solid lines) and the future monthly averages (dashed lines) the same pattern is maintained, with no significant differences between the values.

In the case of the points located in the western Mediterranean, the wind power in the summer time is lower, compared with winter time when high values. The points M3 and M7 present the highest values each month. In M2 the variability is not so accentuated. As regards the eastern Mediterranean an unusual feature appears in the two points located in the Aegean Sea (M10 and M11).
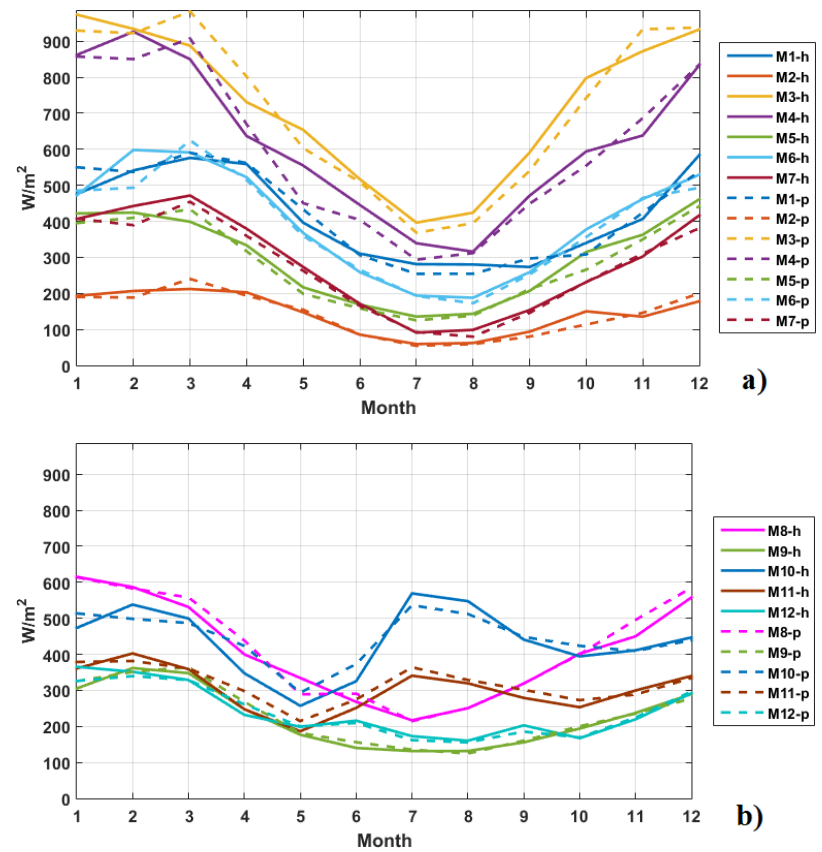

Fig. 3. Monthly variability of the wind power for all points at the hub height of $80 \mathrm{~m}$, historical data (M-h) and projections of the future data (M-p); (a) Points located in western Mediterranean (from M1 to M7), (b) Points located in eastern Mediterranean (from M8 to M12).

The seasonal variability of the mean wind power in each point can be observed also from Figure 4 where the values computed for winter (computed as the mean of all data from October to March) and summer (computed as the mean of all data from April to September) are presented. The small difference between the calculated winter and summer averages in the points M10 and M11cand is observed also in this figure.

However, depending on the wind turbine characteristics, the electrical power is produced only for a range of wind speeds defined by the cut-in and cut-off values. Many types of turbines use a cut-in the value of $3.5 \mathrm{~m} / \mathrm{s}$ wind speed and for the cut-out $25 \mathrm{~m} / \mathrm{s}$. For both available data (historical and projections), the percentage of $U_{80}$ that are inside the functional range above mentioned was computed in each point and the results are illustrated in Figure 5. The point M3 located in Golf of Lion presents the highest value (about $80 \%$ ), but close values have been calculated in M4, M6, M8, M10 and M11 (higher than 75\%).

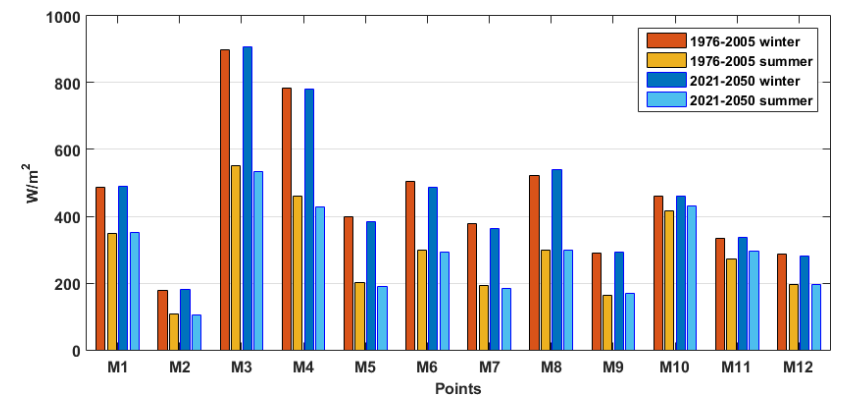

Fig. 4. Seasonal variability of the wind power at the hub height of $80 \mathrm{~m}$, for historical and future data.

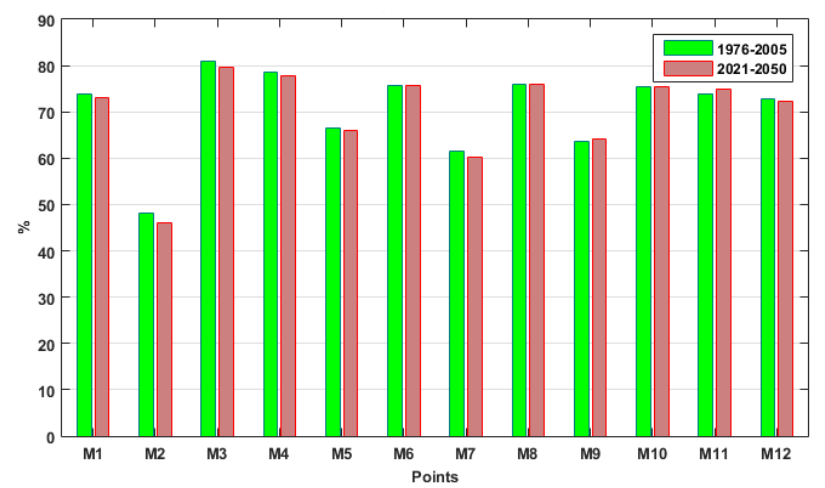

Fig. 5. Percentage of the wind speeds $\left(U_{80}\right)$ in the range between the cut-in and cut-off wind speeds (functional range $3.5-25 \mathrm{~m} / \mathrm{s}$ ).

\section{Conclusions}

The analysis of the wind power potential in twelve reference locations in the Mediterranean Sea was performed considering historical wind fields for a 30year period (1976-2005), and also projections of the wind fields under RCP4.5 scenario (2021-2050). Both wind fields were simulated by the same RCM, namely RCA4.5.

The climate change impact on the wind energy resources was also investigated by performing comparisons between historical and projected wind power. No important differences between both data were observed. In $50 \%$ of the points (M1, M3, M4, M6, M8, and M10) the values computed for wind power are elevated. In the point M3, located in Golf of Lion, are the highest values of the mean wind power and percentage of the wind speeds $\left(U_{80}\right)$ in the functional range of the turbine. On the other hand, in the points M10 and M11 located in the Aegean Sea there are high values of wind power and also with a more uniform pattern along the year. 


\section{Acknowledgments}

This work was carried out in the framework of the research project REMARC (Renewable Energy extraction in MARine environment and its Coastal impact), supported by the Romanian Executive Agency for Higher Education, Research, Development and Innovation Funding - UEFISCDI, grant number PN-III-P4IDPCE-2016-0017.

The wind data used in this study have been obtained from the EURO-CORDEX data servers.

\section{References}

1. WindEurope, Breaking new ground, Report September (2018) https://windeurope.org/aboutwind/reports/breaking-new-ground/

2. J. Appiott, A. Dhanju, B. Cicin-Sain, Encouraging Renewable Energy in the Offshore Environment. Ocean Coast. Manag. 90, 58-64 (2014)

3. IRENA, Offshore innovation widens renewable energy options: Opportunities, challenges and the vital role of international co-operation to spur the global energy transformation (Brief to G7 policy makers), International Renewable Energy Agency, Abu Dhabi (2018)

4. GWEC, Global Wind Report-Annual Market Update 2017 https://gwec.net/publications/global-wind-report-2/

5. F. Onea, L. Deleanu, L. Rusu, C. Georgescu, Evaluation of the wind energy potential along the Mediterranean Sea coasts, Energy Exploration \& Exploitation, $34 \quad$ (5), $\quad 766-792 \quad$ (2016) http://dx.doi.org/10.1177/0144598716659592

6. G. Gaudiosi, C. Borri, Offshore wind energy in the mediterranean countries, Revue des Energies Renouvelables SMEE 10, 173-188 (2010)

7. D. Ganea, V. Amorțilă, E. Mereuță, E. Rusu, A Joint Evaluation of the Wind and Wave Energy Resources Close to the Greek Islands, Sustainability 9(6), 1025 (2017) https://doi.org/10.3390/su9061025

8. E.I. Zountouridou, G.C. Kiokes, S. Chakalis, P.S. Georgilakis, N.D. Hatziargyriou, Offshore floating wind parks in the deep waters of Mediterranean Sea, Renewable and Sustainable Energy Reviews 51, 433-448 (2015).

9. F. Onea, E. Rusu, Efficiency assessments for some state of the art wind turbines in the coastal environments of the Black and the Caspian seas, Energy Exploration \& Exploitation 34(2), 217-234 (2016) https://doi.org/10.1177/0144598716629872

10. I. Balog, P.M. Ruti, I. Tobin, V. Armenio, R. Vautard, A numerical approach for planning offshore wind farms from regional to local scales over the Mediterranean, Renewable Energy 85, 395405 (2016)

11. Onea, F., Rusu, L., Evaluation of Some State-OfThe-Art Wind Technologies in the Nearshore of the Black Sea, Energies 11(9), 2452 (2018)
12. I., Tobin, S. Jerez, R. Vautard, F. Thais, F., E. van Meijgaard, A. Prein, et al., Climate change impacts on the power generation potential of a European mid-century wind farms scenario, Environmental Research Letters 11(3), 034013 (2016).

13. J. Moemken, M. Reyers, H. Feldmann, J.G. Pinto, Future changes of wind speed and wind energy potentials in EURO- CORDEX ensemble simulations, Journal of Geophysical Research: Atmosphere https://doi.org/10.1029/2018JD028473.

14. J. Weber, J. Wohland, M. Reyers, J. Moemken, C. Hoppe, J.G. Pinto, D. Witthaut, Impact of climate change on backup energy and storage needs in winddominated power systems in Europe, PloS one 13(8), p.e0201457 (2018) https://doi.org/10.1371/journal.pone.0201457

15. L. Rusu, M. Bernardino, C. Guedes Soares, Influence of Wind Resolution on the Prediction of Waves Generated in an Estuary, Journal of Coastal Research SI 56, 1419-1423 (2009) http://egeo.fcsh.unl.pt/ICS2009/_docs/ICS2009_Volume_II 1419.1423 L.Rusu_ICS2009.pdf

16. L. Rusu, M. Bernardino, C. Guedes Soares, Influence of the wind fields on the accuracy of numerical wave modelling in offshore locations, Proceedings of the $27^{\text {th }}$ International Conference on Offshore Mecanics and Arctic Engineering OMAE2008, June 15-20, Estoril, Portugal, AMER Soc MECHANICAL ENG., New York 4, 637-644 (2008)

17. R.H. Moss, J.A. Edmonds, K.A. Hibbard, M.R. Manning, S.K. Rose, et al., The next generation of scenarios for climate change research and assessment, Nature 463(7282), 747-756 (2010)

18. M.G. Sotillo, R. Aznar, F. Valero, The 44-year Mediterranean HIPOCAS wind database: A useful tool to analyse offshore extreme wind events from a long-term regional perspective, Coastal Engineering 55(11), 930-943 (2008)

19. M. Herrmann, S. Somot, S. Calmanti, C. Dubois, F. Sevault, Representation of spatial and temporal variability of daily wind speed and of intense wind events over the Mediterranean Sea using dynamical downscaling: impact of the regional climate model configuration, Natural Hazards and Earth System Sciences 11, 1983-2001 (2011)

20. EURO - CORDEX Guidelines. Available online: http://www.eurocordex.net/imperia/md/content/csc/cordex/eurocordex-guidelines-version1.0-2017.08.pdf

21. D. Jacob, J. Petersen, B. Eggert, A. Alias, O.B. Christensen, et al., EURO-CORDEX: new highresolution climate change projections for European impact research, Reg Environ Change 14, 563-578 (2014) doi:10.1007/s10113-013-0499-2.

22. E. Kjellström, L. Bärring, G. Nikulin, C. Nilsson, G. Persson, G. Strandberg, Production and use of regional climate model projections - A Swedish 
perspective on building climate services, Climate services 2, 15-29 (2016)

23. G. Boyle, Renewable energy: power for a sustainable future, Oxford University Press (1996)

24. A. Colmenar-Santos, J. Perera-Perez, D. BorgeDiez, Offshore wind energy: A review of the current status, challenges and future development in Spain, Renewable and Sustainable Energy Reviews 64, 118 (2016).

25. R. Stull, Practical Meteorology: an Algebra Based Survey of Atmospheric Science, Univ British Columbia, Canada (2016) 